\title{
Isolation and Characterization of Chondroitin Sulfates from Sturgeon (Acipenser sinensis) and Their Effects on Growth of Fibroblasts
}

\author{
A-Rang IM, Youmie PARK, and Yeong Shik KIM* \\ Natural Products Research Institute, College of Pharmacy, Seoul National University; Seoul 151-741, Korea. \\ Received March 29, 2010; accepted May 20, 2010; published online May 24, 2010
}

\begin{abstract}
Chondroitin sulfate (CS) is a glycosaminoglycan that composed of hexosamine (D-galactosamine) and hexuronic acid (D-glucuronic acid) unit arranged in an alternating unbranched sequence. CS is an essential component of the extracellular matrix (ECM) of connective tissue. It is mainly covalently attached to core proteins in the form of proteoglycans so that it exhibits specific interactions with proteins for cell growth, differentiation, division and migration. In this study, CSs were purified from the cartilage and backbone of sturgeon (Acipenser sinensis). To characterize their biochemical properties, we performed disaccharide compositional analysis after chondroitinase $\mathrm{ABC}$ digestion, high performance size exclusion chromatography (HPSEC) and ${ }^{1} \mathrm{H}-\mathrm{NMR}$ spectroscopy. We also investigated the effects of CSs on fibroblast proliferation and adhesion to determine whether wound healing was accelerated in vitro and proliferation of different mitogen-activated protein kinases (MAPK) signaling pathways was facilitated. The CS purified from sturgeon cartilage was primarily composed of 4-sulfated CS (88.8\%) and sturgeon backbone CS contains more than $60 \%$ 6-sulfated CS. The average molecular weights of CSs obtained from sturgeon cartilage and backbone were found to be 8 and $43 \mathrm{kDa}$, respectively. Our results showed that both CSs are able to increase cell adhesion, induce proliferation and migration on fibroblasts and may accelerate wound healing by inducing MAPK signaling pathways.
\end{abstract}

Key words chondroitin sulfate; sturgeon; characterization; fibroblast; proliferation

Glycosaminoglycans (GAGs) consist of a linear polysaccharide chain with a repeating disaccharide unit of hexosamine (D-glucosamine or D-galactosamine) and uronic acid (D-glucuronic acid or L-iduronic acid). Chondroitin sulfate (CS) is composed of hexosamine (D-galactosamine) and hexuronic acid (D-glucuronic acid) disaccharide unit, which is arranged in an alternating unbranched sequence. CS has been isolated from various natural sources including mammalian species (bovine, porcine, and chicken cartilage) and marine species (sharks, squids, and skates). ${ }^{1-4)} \mathrm{CS}$ is an essential component of the extracellular matrix (ECM) of connective tissue. It is mainly covalently attached to core proteins in the form of proteoglycans so that it exhibits specific interactions with proteins for cell growth, differentiation, division and migration. ${ }^{5)}$ In addition, CS plays important roles in the elasticity, function of the articular cartilage, wound healing, the central nervous system, and chondrocytes. ${ }^{6-10)}$

Wound healing is a complex process that is a result of mechanical and chemical injuries. It has been divided into three main phases: inflammation, proliferation and tissue remodeling. Fibroblasts play an important role in wound healing and require a growth factor for their activation and proliferation. ${ }^{1-13)}$ The action of CS in wounds affects the size, orientation and the degree of fibroblasts present in the wound. CS stimulates the proliferation of human fibroblasts derived from both normal skin and chronic wounds. CS helps to mediate fibroblast growth factor-2 (FGF-2)-induced cell proliferation by binding to FGF-2. It also helps to regulate cell adhesion and enhance cell spreading and migration. ${ }^{7,14,15)}$

Sturgeon (Acipenser sinensis) is a globally important wildlife resource that contributes as an important element of local food supply. ${ }^{16)}$ Sturgeon's cartilage contains biologically active substances such as collagen, glucosamine, and CS. ${ }^{17-19)}$ In this study, the purified CSs from sturgeon cartilage and backbone were characterized using strong anion-exchange (SAX) HPLC, high performance size-exclusion chro- matography (HPSEC) and ${ }^{1} \mathrm{H}-\mathrm{NMR}$. We also determined the effect of the purified CS on fibroblast cell adhesion, proliferation and migration.

\section{MATERIALS AND METHODS}

Materials Sturgeon was purchased at a local store in Seoul, Korea. Control CS from bovine trachea was purchased from New Zealand Pharmaceuticals (Palmerston North, New Zealand) and its purity was assessed based on USP CS. ${ }^{22}$ Authentic CS from shark cartilage and two other CS samples used as MW standards were obtained from Seikagaku Co. (Tokyo, Japan). Hyaluronic acids $(100,130,1690 \mathrm{kDa})$ were also acquired to use as MW standards. Chondroitinase ABC from Proteus vulgaris, sodium carbonate, trichloroacetic acid solution, cetylpyridinium chloride, sodium chloride and tris [hydroxymethyl] aminomethane $\left(\right.$ Trizma $^{\circledR}$ base) were purchased from Sigma (St. Louis, MO, U.S.A.). The dialysis membrane (Spectra/Por ${ }^{\circledR}$ 1, MWCO 6-8 kDa) was purchased from Spectrum ${ }^{\circledR}$ Laboratories (Rancho Dominguez, CA, U.S.A.). Alcalase ${ }^{\circledR}$ (2.4 Anson units/g) from Bacillus licheniformis was purchased from Novozymes (Bagsvaerd, Denmark). Human dermal fibroblast cells were obtained from the Biospectrum Life Science Institute (Gyunggi Province, Korea). Dulbecco's modified Eagle's medium (DMEM) and fetal bovine serum were obtained from Thermo Scientific HyClone (Waltham, MA, U.S.A.). Dulbecco's phosphate-buffered saline (D-PBS) and 3-(4,5-dimetylthiazol-2-yl)-2,5-diphenyltetrazolium bromide (MTT) were purchased from Sigma-Aldrich (St. Louis, MO, U.S.A.). Anti-p38, p-p38, c-Jun $N$-terminal kinases (JNK1), pJNK1, extracellular signal-regulated kinase 1 (ERK1), pERK1/2, $\beta$ actin, goat anti-mouse horseradish peroxidase (HRP)-conjugated secondary antibody and goat anti-rabbit (HRP)-conjugated secondary antibody were purchased from Santa Cruz (CA, U.S.A.). We used nitrocellulose membrane (PALL, Port 
Washington, NY, U.S.A.), WEST-SAVE UP ${ }^{\mathrm{TM}}$ luminal-based ECL reagent (LabFrontier, Seoul, Korea), dimethyl sulfoxide (Bioshop, Burlington, Canada), a wound healing assay kit (Culture-Insert, Ibidi, München, Germany) and a protein assay reagent (Bio-Rad, Vancouver, Canada).

Purification of CS from Sturgeon The bones and cartilage of sturgeon were cleaned, lyophilized and ground. CS was isolated using a method according to our previous study. $^{20)}$ The dried powder was suspended in $50 \mathrm{~mm}$ sodium carbonate buffer $(\mathrm{pH} 7.0)$ containing alcalase solution $(5 \%)$ and was then incubated for $12 \mathrm{~h}$ at $60^{\circ} \mathrm{C}$ and $200 \mathrm{rpm}$ in a shaking incubator. After boiling for $10 \mathrm{~min}$ to inactivate the protease, the sample solution was filtered and cooled at $4{ }^{\circ} \mathrm{C}$. The trichloroacetic acid solution $(6.1 \mathrm{M})$ was mixed with the filtrate to a final concentration of $5 \%(\mathrm{v} / \mathrm{v})$, and the precipitated proteins were removed by spinning down at $887 \times \boldsymbol{g}$ for $30 \mathrm{~min}$ at $4{ }^{\circ} \mathrm{C}$. After ethanol $(80 \%, \mathrm{v} / \mathrm{v})$ precipitation, the solution was centrifuged at $887 \times \boldsymbol{g}$ for $30 \mathrm{~min}$ at $4{ }^{\circ} \mathrm{C}$. After the precipitate was dried, it was dissolved in water, mixed with cetylpyridinium chloride solution (final 1\% w/v) and stored for $1 \mathrm{~h}$ at room temperature. It was then centrifuged again at $887 \times \boldsymbol{g}$ for $30 \mathrm{~min}$ at $4^{\circ} \mathrm{C}$ and the precipitate was recovered. The precipitate was dissolved in $2.5 \mathrm{~m}$ of sodium chloride, precipitated by ethanol $(80 \%, \mathrm{v} / \mathrm{v})$ and centrifuged at $887 \times \boldsymbol{g}$ for $30 \mathrm{~min}$ at $4^{\circ} \mathrm{C}$. The final precipitate was dissolved in water, dialyzed $(\mathrm{MWCO} 6-8 \mathrm{kDa})$ for $2 \mathrm{~d}$ at $4{ }^{\circ} \mathrm{C}$ and freeze-dried.

Chemical Characterization of CS The chemical composition and purities of the CS were determined by the validated disaccharide analytical method after chondroitinase ABC digestion. ${ }^{21)}$ To make the sample solution, $100 \mu \mathrm{l}$ of control CS $(10 \mathrm{mg} / \mathrm{ml})$ and CS test samples $(10 \mathrm{mg} / \mathrm{ml})$ were mixed with $800 \mu \mathrm{l}$ of Tris-acetate buffer $\left(50 \mathrm{~mm}\right.$ Trizma ${ }^{\circledR}$ base and $60 \mathrm{~mm}$ of sodium acetate, $\mathrm{pH} 8.0$ ), respectively. The samples were depolymerized with $100 \mu \mathrm{l}$ of chondroitinase ABC $(1 \mathrm{mU} / \mu \mathrm{l})$ overnight at $37^{\circ} \mathrm{C}$. After heating for $5 \mathrm{~min}$ and filtering on $0.2 \mu \mathrm{m}$ syringe filters (PALL Life Sciences, Ann Arbor, MI, U.S.A.), reaction mixtures were injected $(100 \mu \mathrm{g} / \mu \mathrm{l})$ into a SAX-HPLC using a Hypersil SAX column $(4.6 \times 250 \mathrm{~mm}, 5 \mu \mathrm{m})$ from Thermo Hypersil-Keystone (Bellefonte, PA, U.S.A.). After the sample injection, the column was washed with water $(\mathrm{pH} 3.5)$ corresponding to one column volume $(\mathrm{CV})$ for $4 \mathrm{~min}$ and a linear gradient of 0 $1.0 \mathrm{M}$ of $\mathrm{NaCl}(\mathrm{pH} 3.5,10 \mathrm{CV})$ was used. The absorbance was monitored at $232 \mathrm{~nm}$ and the flow rate was $1.0 \mathrm{ml} / \mathrm{min}$. The chemical composition and purity of the samples were confirmed by the validated disaccharide analytical a method as previously described. ${ }^{22)}$ Their purity was determined by comparing the total peak area of the disaccharides $(\Delta \mathrm{Di}-0 \mathrm{~S}$, $\Delta$ Di-6S, $\Delta$ Di-4S, $\Delta$ Di-2,6diS) to control CS.

We used HPSEC equipped with a TSK G6000 PWXL column (7.5 mm $\times 300 \mathrm{~mm}$, Tokyo, Japan) and a TSK guard column (7.5 mm $\times 75 \mathrm{~mm}$, Tokyo, Japan) and ran MW-standard samples to determine the average MW of the CS test sample. ${ }^{23)}$ The mobile phase was $0.1 \mathrm{M}$ of $\mathrm{NaCl}$ and the flow rate was $1.0 \mathrm{ml} / \mathrm{min}$. The UV absorption was measured at $206 \mathrm{~nm}$. Three kinds of hyaluronic acids (average MW 1690, $130,100 \mathrm{kDa}$ ) and two CS samples (average MW 40, $15 \mathrm{kDa})$ were used as MW-standard samples. These samples were individually injected $(500 \mu \mathrm{g} / 100 \mu \mathrm{l})$ into the high performance liquid choromatography (HPLC) in order to derive a MW calibration curve, which was established by plotting the logarithm of the MW against each retention time of the MW standards. The average MW of the CS test sample was determined via the MW calibration curve.

${ }^{1}$ H-NMR Spectroscopy The structural integrity of the CS test sample was observed using ${ }^{1} \mathrm{H}-\mathrm{NMR}$ spectroscopy. One milligram of each sample was exchanged with $1 \mathrm{ml}$ of $\mathrm{D}_{2} \mathrm{O}$ (Sigma, St. Louis, MO, U.S.A.) and was then lyophilized. The dried samples were re-dissolved in $600 \mu \mathrm{l}$ of $\mathrm{D}_{2} \mathrm{O}$ and were analyzed using a $500 \mathrm{MHz}$ BRUKER.

Cell Culture Fibroblasts were maintained at sub-confluence in $95 \%$ air and $5 \% \mathrm{CO}_{2}$ humidified atmosphere at $37^{\circ} \mathrm{C}$. The fibroblasts were grown in DMEM with $10 \%$ fetal bovine serum (FBS) containing $25 \mathrm{~mm} N$-(2-hydroxyethyl)piperazine- $N^{\prime}$-2-ethanesulfonic acid (HEPES), $100 \mathrm{units} / \mathrm{ml}$ of penicillin and $100 \mu \mathrm{g} / \mathrm{ml}$ of streptomycin.

Cell Adhesion Assay and Proliferation Assay Fibroblasts were plated at a density of $5 \times 10^{3}$ cells/well with DMEM containing 1\% FBS (starvation medium) and various concentration of samples in a 96-well plate for adhesion assay. First, for proliferation assay, fibroblasts were plated at a density of $5 \times 10^{3}$ cells/well with DMEM containing $1 \%$ FBS (starvation medium) in a 96-well plate and were incubated at $37^{\circ} \mathrm{C}$ for $24 \mathrm{~h}$. Samples of various concentrations were treated in a 96-well plate after additional incubation at $37^{\circ} \mathrm{C}$. Second, cell adhesion was determined after $3 \mathrm{~h}, 6 \mathrm{~h}$, $12 \mathrm{~h}, 24 \mathrm{~h}$ and cell proliferation was determined after $72 \mathrm{~h}$ by reduction of 3-(4,5-dimetylthiazol-2-yl)-2,5-diphenyltetrazolium bromide (MTT) to formazan. After removing the medium, $100 \mu \mathrm{l}$ of MTT $(0.5 \mathrm{mg} / \mathrm{ml}$ in D-PBS $)$ was added into each well and then incubated at $37^{\circ} \mathrm{C}$. Then, MTT was removed and dimethyl sulfoxide was added to dissolve the formazan crystals. The resulting absorbance was assayed at $540 \mathrm{~nm}$ using a microplate reader (Molecular Devices, Sunnyvale, CA, U.S.A.).

In Vitro Wound Healing Assay To determine the migration of fibroblasts, cells were seeded at a density of $1 \times 10^{3}$ cells/well with DMEM containing $1 \%$ FBS (starvation medium) in a Culture-Insert (wound healing assay kit) and incubated at $37^{\circ} \mathrm{C}$ for $24 \mathrm{~h}$. We used sterile tweezers to remove the Culture-Insert from the dish filled with cell free starvation medium containing CS samples. After 6, 12 and $24 \mathrm{~h}$ of incubation we observed the samples by microscopy and took photographs using CKX41 microscopy (Olympus, Japan) at $100 \times$ magnification.

Protein Extraction and Western Blotting Fibroblasts $\left(5 \times 10^{4}\right.$ cells/well $)$ were seeded with DMEM containing $1 \%$ FBS (starvation medium) in a 6-well plate and incubated at $37^{\circ} \mathrm{C}$ for $24 \mathrm{~h}$. Cells were treated for an additional $0-6 \mathrm{~h}$ of incubation at $37^{\circ} \mathrm{C}$. Cells were then lysed in a Totex buffer (20 mм HEPES (pH 7.9), $350 \mathrm{~mm} \mathrm{NaCl,} \mathrm{20 \%} \mathrm{glycerol,} \mathrm{1 \%}$ NP-40, $1 \mathrm{~mm} \mathrm{MgCl}_{2}, 0.5 \mathrm{~mm}$ ethylenediaminetetraacetic acid (EDTA) and $0.1 \mathrm{~mm}$ ethylene glycol bis(2-aminoethylether)$N, N, N^{\prime}, N^{\prime}$-tetraacetic acid (EGTA) (pH 8.0)). Samples were electrophoresed to separate $20 \mu \mathrm{g}$ of protein on a $10 \%$ sodium dodecyl sulfate (SDS)-polyacryamide gel. The proteins were then transferred to a nitrocellulose membrane. After being blocked with $5 \%$ skim milk for $1 \mathrm{~h}$, the membrane was incubated with the first antibody (anti-p38, p-p38, JNK1, pJNK, ERK1, pERK1/2, and actin, respectively). We then added the second antibody (goat anti-mouse (HRP)-con- 
Table 1. Chemical Characterization of Authentic Chondroitin Sulfate and Sturgeon Chondroitin Sulfates

\begin{tabular}{|c|c|c|c|c|c|c|c|}
\hline \multirow{2}{*}{ CS source } & \multirow{2}{*}{$\begin{array}{c}\text { Purity } \\
(\%)\end{array}$} & \multirow{2}{*}{$\begin{array}{l}\text { Yield } \\
(\%)\end{array}$} & \multicolumn{4}{|c|}{ Disaccharide ratio $(\%)^{a)}$} & \multirow{2}{*}{$\begin{array}{c}\text { Molecular } \\
\text { weight }(\mathrm{kDa})\end{array}$} \\
\hline & & & $\Delta$ Di-0S: & $-6 \mathrm{~S}:$ & $-4 \mathrm{~S}:$ & -2,6diS: & \\
\hline Control CS & 100 & $X$ & 7.4 & 41.9 & 50.7 & 0 & 14 \\
\hline Shark cartilage & 98.2 & 9.7 & 2.3 & 40.8 & 34.9 & 22 & 60.6 \\
\hline Sturgeon cartilage & 91.1 & 10.5 & 4.0 & 7.2 & 88.8 & 0 & 8 \\
\hline Sturgeon backbone & $100>$ & 13.3 & 9.9 & 66.2 & 23.9 & 0 & 43.4 \\
\hline
\end{tabular}

a) $\Delta \mathrm{Di}-0 \mathrm{~S}(\Delta \mathrm{UA}-[1 \rightarrow 3]$-GalNAc); $\Delta \mathrm{Di}-6 \mathrm{~S}(\mathrm{CS}$ C: $\Delta \mathrm{UA}-[1 \rightarrow 3]-$ GalNAc-6S); $\Delta \mathrm{Di}-4 \mathrm{~S}(\mathrm{CS}$ A: $\Delta \mathrm{UA}-[1 \rightarrow 3]-G a l N A c-4 \mathrm{~S}) ; \Delta \mathrm{Di}-2,6 \mathrm{diS}(\mathrm{CS}$ D: $\Delta \mathrm{UA}-2 \mathrm{~S}-[1 \rightarrow 3]-\mathrm{GalNAc}-6 \mathrm{~S})$.

jugated and goat anti-rabbit (HRP)-conjugated secondary antibody. An enhanced chemiluminescence (ECL) detection kit was used to develop the membrane. The signal obtained from the membrane was photographed using an image analyzer (LAS 1000, Fuji, Japan). The target bands were quantified using UN-SCAN-IT ${ }^{\mathrm{TM}}$ software ver. 6.1 (Silk Scientific Corp., U.S.A.).

Statistics The data were summarized as means \pm standard deviation (S.D.) from three independent experiments. A one-way analysis of variance (ANOVA) followed by $t$-test was applied to assess the statistical significant of multiple comparisons. The level of statistically significant difference was set at $p<0.05$.

\section{RESULTS}

Preparation of CS from Sturgeon Cartilage and Backbone Shark cartilage, which is a commercial CS source, was used as a raw material to compare the purity and the yield of CS purified from sturgeon cartilage and backbone. The CS samples were purified as white powders. The yield $(\%)$ and purity (\%) were determined by SAX-HPLC analysis of CS disaccharides derived by enzymatic depolymerization as previously reported. ${ }^{21}$ The purity of CS from sturgeon cartilage was $91.1 \%$. However, the CS isolated from the sturgeon backbone exhibited more than $100 \%$ purity compared to control CS. The yield of CS from cartilage and backbone was $10.5 \%$ and $13.3 \%$, respectively (Table 1 ).

Chemical Characterization of CS from Sturgeon Cartilage The samples purified from sturgeon cartilage and backbone were depolymerized to completion using chondroitinase $\mathrm{ABC}$. CS disaccharides derived by enzymatic depolymerization were quantitatively analyzed using SAXHPLC. The CS purified from sturgeon cartilage was composed of mono-sulfated disaccharides $\triangle \mathrm{Di}-0 \mathrm{~S}(4.0 \%$, a), $\Delta \mathrm{Di}-6 \mathrm{~S}(7.2 \%, \mathrm{~b})$ and $\Delta \mathrm{Di}-4 \mathrm{~S}(88.8 \%, \mathrm{c})$. The CS purified from sturgeon backbone consisted of mono-sulfated disaccharides $\Delta$ Di-0S $(9.9 \%$, a), $\Delta$ Di-6S $(66.2 \%, b)$ and $\Delta \mathrm{Di}-4 \mathrm{~S}$ $(23.8 \%, \mathrm{c})$ (Table 1$).$ In order to determine the average molecular weight, the MW-standard samples and the CS samples were analyzed by HPSEC (Table 1). The average molecular weights of the CS obtained from shark cartilage, sturgeon cartilage and sturgeon backbone were found to be 60,8 , and $43 \mathrm{kDa}$, respectively. The CS obtained from the sturgeon cartilage has the lowest molecular weight among purified samples.

${ }^{1} \mathrm{H}-\mathrm{NMR}$ spectroscopy was performed to confirm the disaccharide composition and the structural integrity of the CS samples. The results were compared to CS from shark cartilage (Fig. 1A). For sturgeon $\mathrm{CS}$, a characteristic signal at
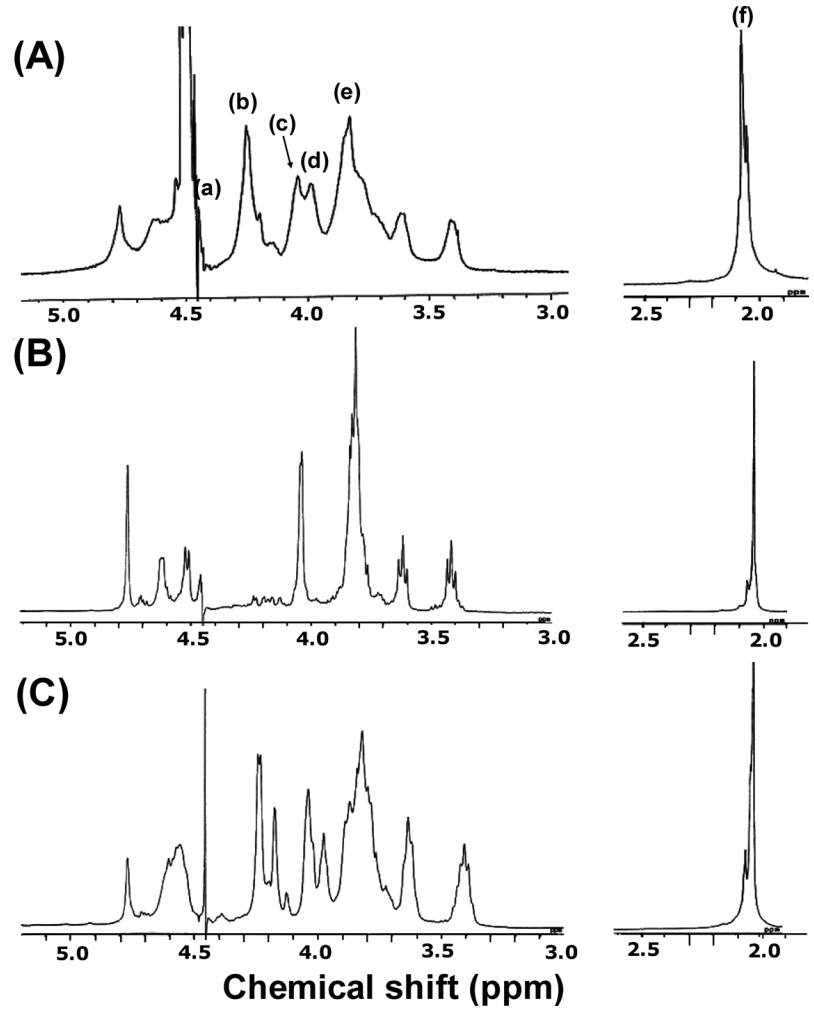

Fig. 1. ${ }^{1}$ H-NMR Spectra of CS Samples (A) Shark Cartilage CS, (B) Sturgeon Cartilage CS and (C) Sturgeon Backbone CS

(a) H-4 of GalNAc, (b) H-1 of GalNAc, (c) H-6 of GalNAc6S, (d) H-4 of GalNAc6S, (e) H-2 of GalNAc and (f) $N$-acetyl signals of GalNAc4S and GalNAc6S

$4.4 \mathrm{ppm}$ was assigned as $\mathrm{H} 4$ of the $O$-sulfate substituted on the C4-position of GalNAc. ${ }^{24,25)}$ The CS sample from shark cartilage had a characteristic signal at $4.0 \mathrm{ppm}$ (Fig. 1A). The CS from sturgeon cartilage contained fewer sulfate groups on the C4-postion of GalNAc, which showed a downfield signal at $4.4 \mathrm{ppm}$ (Fig. 1B). This result is also consistent with the composition analysis of disaccharide by HPLC (Table 1). The signal intensity of the two overlapping peaks indicated methyl groups between 1.95 and $2.05 \mathrm{ppm}$ and confirmed the above result.

Effect of CS on Fibroblast Adhesion and Proliferation We determined the adhesion effect of CS on fibroblasts after $3,6,12$, and $24 \mathrm{~h}$ of incubation with CS samples. After $3 \mathrm{~h}$ incubation, cell adhesion to wells treated with CS $100 \mu \mathrm{g} / \mathrm{ml}$ purified from sturgeon cartilage was $113.8 \%$ compared to the control (Fig. 2A). The cell adhesion treated with CS from sturgeon backbone was $114.8 \%$ compared to the control (Fig. 2A). For each CS sample, cell adhesion to wells was significantly higher than that of control wells. After adhering to 


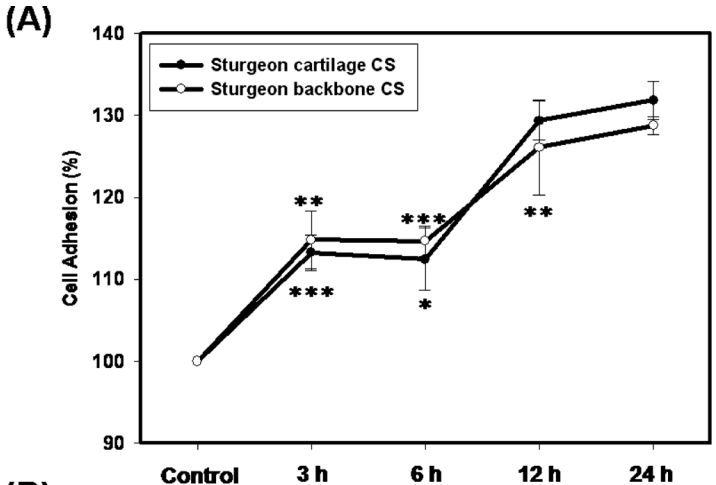

(B)

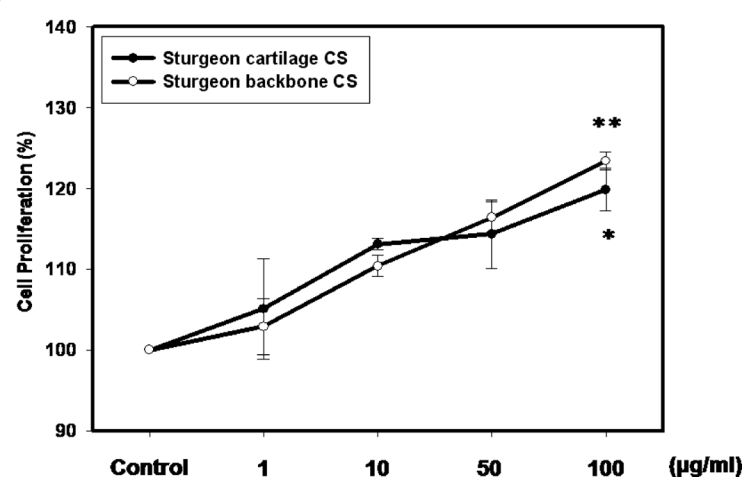

Fig. 2. The Effect of Sturgeon Cartilage and Backbone CS on (A) Cell Adhesion and (B) Cell Proliferation

The control indicates that cells are not treated with any samples. Data were obtained from at least three independent experiments and are expressed as mean \pm S.D. $* p<0.01, * * p<0.005$, and $* * * p<0.001$ versus untreated control cells.

wells within $24 \mathrm{~h}$, cells started to proliferate. When incubation time was longer to $72 \mathrm{~h}$, the ratio of cell proliferation compared to control increased in a dose-dependent manner and reached $119.9 \%$ on incubation with $100 \mu \mathrm{g} / \mathrm{ml}$ of the purified CS from sturgeon cartilage. On the other hand, the proliferation increased to $123.4 \%$ when cells were incubated with $100 \mu \mathrm{g} / \mathrm{ml}$ of purified CS from sturgeon backbone (Fig. 2B).

In Vitro Wound Healing Assay The effect of CSs from sturgeon cartilage and backbone on the migration of fibroblasts was tested in an in vitro model. The cell-free area was repopulated by fibroblasts through the combined action of migration and proliferation. Fibroblasts treated with CS started to migrate into the cell-free area at $6 \mathrm{~h}$ and the cellfree area was almost completely full at $24 \mathrm{~h}$ (Figs. 3G, J). In contrast, fibroblasts without CS treatment were less motile so there were fewer cells in the cell-free area after $24 \mathrm{~h}$ (Fig. 3D). In the wound area, fibroblasts treated with CS moved more quickly than control fibroblasts.

Effect of CS on pERK, pp38 and pJNK Kinases Mitogen-activated protein kinases (MAPKs) regulate physiological processes such as cell proliferation and differentiation. MAPKs form a large kinase complex with extracellular signal-regulated kinase (ERK), Jun kinase (JNK) and p38 MAPK. ${ }^{26,27)}$ MAPKs play an important role in modulating many cellular events, including cell cycle progression, cell proliferation, differentiation, development and apoptosis. ${ }^{28}$ Western blotting showed that both cartilage and bone CSs activate MAPK signaling pathways that are known to support cell proliferation. The levels of phosphorylated ERK and p38

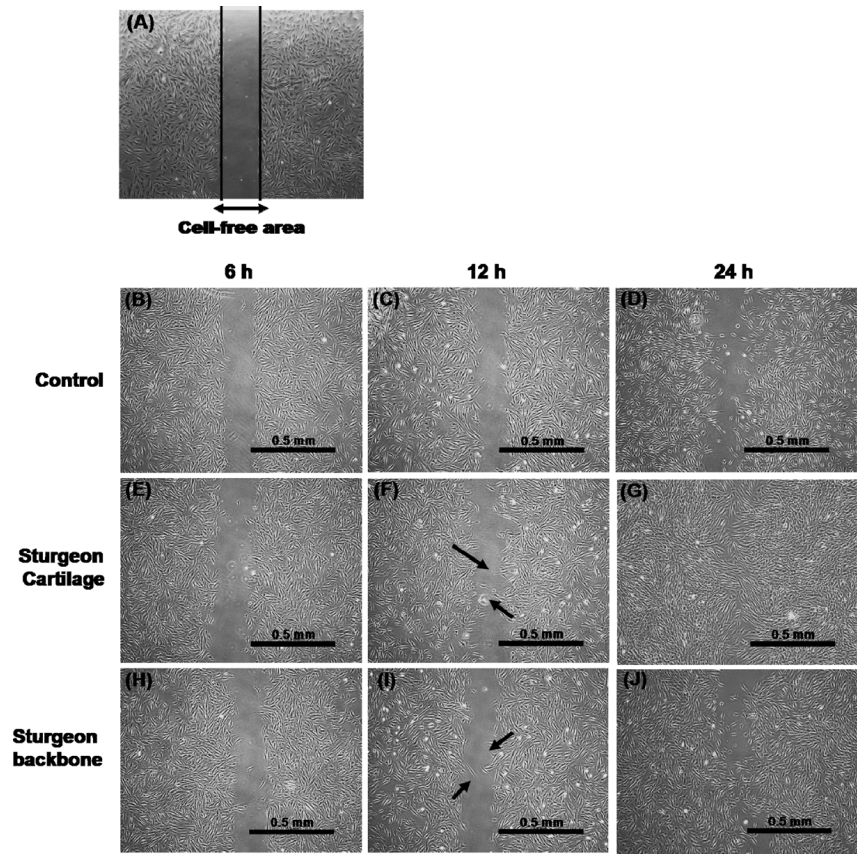

Fig. 3. The Effect of Sturgeon Cartilage and Backbone CS on Fibroblast Migration at Different Incubation Times (A) 0 h, (B) Control 6h, (C) Control $12 \mathrm{~h}$, (D) Control 24h, (E) Sturgeon Cartilage 6h, (F) Sturgeon Cartilage $12 \mathrm{~h},(\mathrm{G})$ Sturgeon Cartilage $24 \mathrm{~h}$, (H) Sturgeon Backbone $6 \mathrm{~h}$, (I) Sturgeon Backbone $12 \mathrm{~h}$ and (J) Sturgeon Backbone $24 \mathrm{~h}$

The control indicates that cells are not treated with any samples. These results were observed by a CKX41 microscopy at $100 \times$ magnification. The scale bar indicates $0.5 \mathrm{~mm}$. Fibroblasts treated with CS started to migrate into the cell-free area at $6 \mathrm{~h}$ and the cell-free area was almost completely full at $24 \mathrm{~h}$.

were increased, but the level of phosphorylated JNK was slightly weaker than ERK and p38. Especially the level of phosphorylated ERK was highly increased compared to control by treatment of backbone CS on incubation for $6 \mathrm{~h}$ (Fig. 4).

\section{DISCUSSION}

The quantification and characterization of CSs from sturgeon cartilage and backbone were performed based on disaccharide composition and average MW. Many spectrophotometric methods, including SAX-HPLC, have been used for the quality control of CS. The content of CS from sturgeon cartilage was $91.1 \%$ and sturgeon backbone CS content was $100 \%$. The ratio of disaccharides showed that CS from sturgeon backbone has the typical disaccharide pattern of CS obtained from shark cartilage. However, CS from sturgeon cartilage has a different disaccharide pattern. Purified CS from sturgeon cartilage is rich in $\triangle \mathrm{Di}-4 \mathrm{~S}(88.8 \%)$. This finding is similar to purified CS from whale cartilage. ${ }^{29)}$ The CS-A is known to be rich [GlcA-GalNAc(4S)] and plays an important role in antioxidant activity ${ }^{30)}$ and prevention of atherosclerosis. ${ }^{31)}$ Nowadays the main source of commercial CS is cartilage from marine animals. Commercial CS-C is prepared from shark cartilage, while commercial CS-A is obtained from whale or porcine cartilages. For centuries, whales have been caught for meat and as a source of raw materials. By the middle of the 20th century, however, whaling business had left many species seriously endangered, leading to the hot debate of whaling in the world. In this perspective, sturgeon can 
(A)
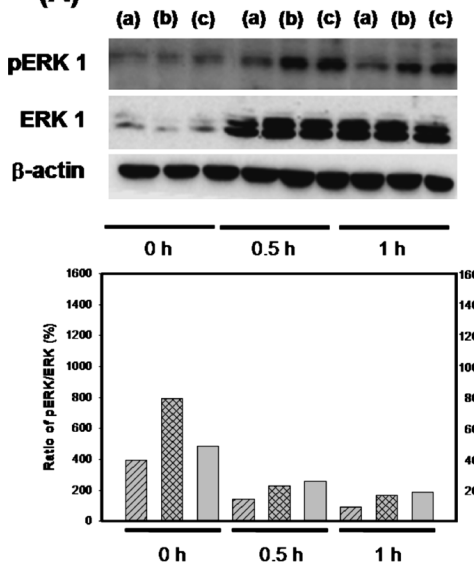

(a) (b) (c) (a) (b) (c) (a) (b) (c)
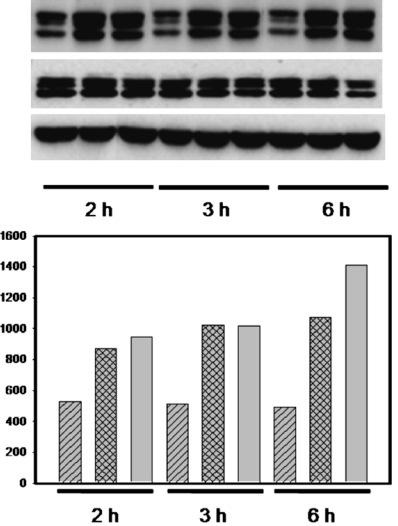

(B)

(a) (b) (c) (a) (b) (c) (a) (b) (c)

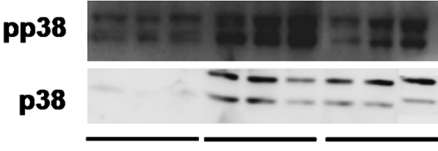

$\mathrm{Oh}$

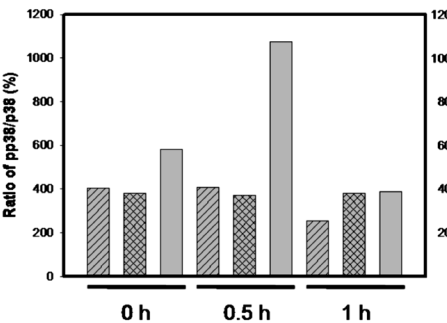

(a) (b) (c) (a) (b) (c) (a) (b) (c)

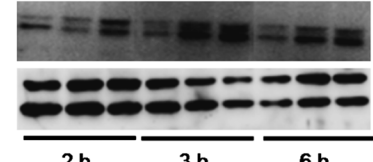

$2 \mathrm{~h} \quad 3 \mathrm{~h} \quad 6 \mathrm{~h}$

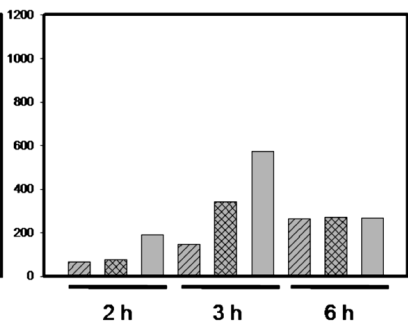

(C)

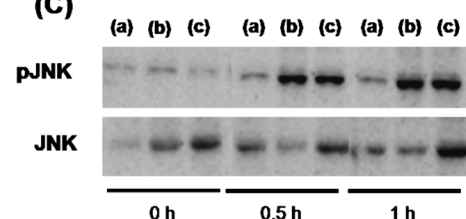

(a) (b) (c) (a) (b) (c) (a) (b) (c)
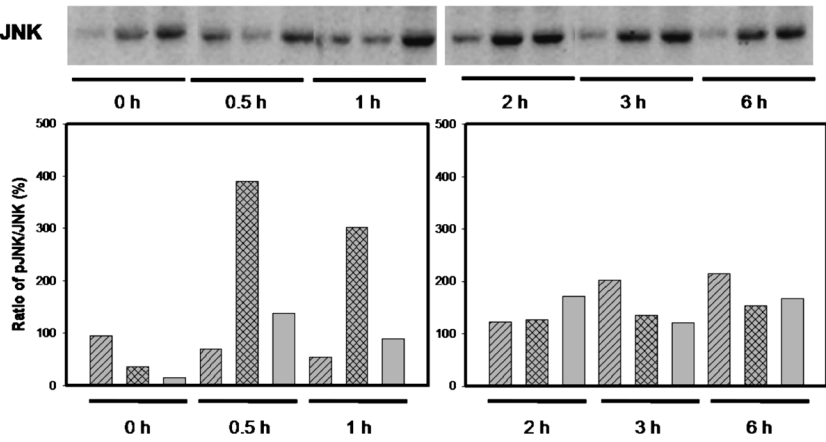

Fig. 4. The Effect of Sturgeon Cartilage and Backbone CS on Phosphorylation of ERK, p38 and JNK (A) pERK/ERK, (B) pp38/p38 and (C) $\mathrm{pJNK} / \mathrm{JNK}$ in MAPK Signaling Pathway

(a) $V_{/}$indicates control (the control indicates that cells are not treated with any samples), (b) indicates sturgeon cartilage CS at $10 \mu \mathrm{g} / \mathrm{ml}$; (c) $\square$ indicates sturgeon backbone CS at $10 \mu \mathrm{g} / \mathrm{ml}$.

be an alternative for the new source of a raw material for CS and sturgeon farming is possible in some countries. ${ }^{32}$ Another uniqueness of CS from the sturgeon cartilage is its molecular weight of $8 \mathrm{kDa}$, because the average molecular weight of CS is generally more than $15 \mathrm{kDa}$. In our previous report, we determined the effect of low molecular weight CS on collagen-induced arthritis, which might be due to better absorption via the gastrointestinal tract and regulation in in- flammatory responses. ${ }^{33)}$

In this study, we showed a stimulatory effect of CS on cell adhesion, proliferation and migration. As wound healing progresses, the injured skin matrix is replaced by a new, collagen-rich matrix synthesized by fibroblasts migrating into the wound. Fibroblasts migrated into the wound site from the surrounding tissue, become activated and begin to synthesize collagen. Therefore, fibroblasts adhesion and migration are essential to wound healing. ${ }^{34)}$ In this study, CS could stimulate fibroblasts to adhere, proliferate, and migrate into the wound space.

To explore the mechanism by which CS induces cell proliferation, we tested the proliferation-related signal transduction pathway (MAPK pathway). JNK and p38 kinases have been shown to play key roles in cellular stress, apoptosis and inflammation. The ERK1/2 pathway plays an important role in cell proliferation and differentiation. ${ }^{35,36)}$ Our results show that CS induces MAPK pathways that may be casually linked to injury and proliferation of specific cell types. In previous reports, GAGs containing CS interact with the FGF family ${ }^{37}$ and controlled the release of FGF. ${ }^{38)} \mathrm{CS}$ interacts with dermal fibroblasts and has a potential role in wound healing, such as cell adhesion, proliferation and matrix deposition. ${ }^{39-41)}$

Based on our results, the purified CSs from sturgeon cartilage and backbone have the potential to enhance the proliferation of fibroblasts in wound healing. In addition, the purified CS in this study could be a valuable substitute for commercially available $\mathrm{CS}$, which is mainly from shark cartilage.

Acknowledgment This work was supported by funding from the National Research Foundation of Korea (NRF) and a Grant from the Korea government (MEST) (No. 20090083533).

\section{REFERENCES}

1) Axelsson I., Heinegard D., Exp. Eye Res., 31, 57-66 (1980).

2) Seno N., Meyer K., Biochim. Biophys. Acta, 78, 258-264 (1963).

3) Srinivasan S. R., Radhakrishinamurthy B., Dalferes E. R. Jr., Berenson G. S., Comp. Biochem. Physiol., 28, 169-176 (1969).

4) Lignot B., Lahogue V., Bourseau P., J. Biotechnol., 103, 281-284 (2003).

5) Bassols A., Massague J., J. Biol. Chem., 263, 3039-3045 (1988).

6) Galtrey C. M., Fawcett J. W., Brain Res. Rev., 54, 1-18 (2007).

7) Zou X. H., Foong W. C., Cao T., Bay B. H., Ouyang H. W., Yip G. W., J. Dent. Res., 83, 880-885 (2004).

8) Gilbert M. E., Kirker K. R., Gray S. D., Ward P. D., Szakacs J. G., Prestwich G. D., Orlandi R. R., Laryngoscope, 114, 1406-1409 (2004).

9) Bayliss M. T., Osborne D., Woodhouse S., Davidson C., J. Biol. Chem., 274, 15892-15900 (1999).

10) Hugenberg S. T., Brandt K. D., Cole C. A., J. Rheumatol., 20, 2128 2133 (1993).

11) Janis J. E., Attinger C. E., Plast. Reconstr. Surg., 117, 12-34 (2006).

12) Taquino L. T., J. Perinat. Neonatal Nurs., 14, 104-118 (2000).

13) Strodtbeck F., Newborn Infants Nurs. Rev., 1, 43-52 (2001).

14) Milev P., Monnerie H., Popp S., Margolis R. K., Margolis R. U., J. Biol. Chem., 273, 21439-21442 (1998).

15) Yang J., Price M. A., Neudauer C. L., Wilson C., Ferrone S., Xia H., Iida J., Simpson M. A., McCarthy J. B., J. Cell Biol., 165, 881-891 (2004).

16) Fontana F., Tagliavini J., Congiu L., Genetica, 111, 359-373 (2001).

17) Kimura S., Comp. Biochem. Physiol. B, 102, 255-260 (1992).

18) Preobrazhenskii A. A., Likhosherstov L. M., Senchenkova S. N., Rodionova A. I., Feshchenko S. P., Biokhimiia, 54, 1235-1246 (1989).

19) Mathews M. B., Biochem. J., 125, 37-46 (1971) 
20) Im A. R., Sim J. S., Park Y. M., Hahn B. S., Toida T., Kim Y. S., Food Sci. Biotechnol., 18, 872-877 (2009).

21) Sim J. S., Im A. R., Cho S. M., Jang H. J., Jo J. H., Kim Y. S., Food Chem., 101, 532-539 (2007).

22) Sim J. S., Jun G., Toida T., Cho S. Y., Choi D. Y., Chang S. Y., Linhardt R. J., Kim Y. S., J. Chromatogr. B, 818, 133-139 (2005).

23) Cho S. Y., Sim J. S., Jeong C. S., Chang S. Y., Choi D. W., Toida T., Kim Y. S., Biol. Pharm. Bull., 27, 47-51 (2004).

24) Mucci A., Schenetti L., Volpi N., Carbohydr. Res., 41, 37-45 (2000).

25) Sakai S., Otake E., Toida T., Goda Y., Chem. Pharm. Bull., 55, 299303 (2007).

26) Johnson G. L., Lapadat R., Science, 298, 1911-1912 (2002).

27) Junttila M. R., Li S. P., Westermarck J., FASEB J., 22, 954-965 (2008).

28) Zhang W., Liu H. T., Cell Res., 12, 9-18 (2002).

29) Sugahara K., Masuda M., Harada T., Yamashina I., Waard P., Vliegenthart J. F., Eur. J. Biochem., 202, 805-811 (1991).

30) Campo G. M., Avenoso A., Campo S., D’Ascola A., Ferlazzo A. M., Sama D., Calatroni A., Cell Biol. Int., 30, 21-30 (2006).

31) Morrison L. M., Murata K., Quilligan J. J., Schjeide O. A., Freeman
L., Circ. Res., 19, 358-363 (1966).

32) Williot P., Sabeau L., Gessner J., Arlati G., Bronzi P., Gulyas T., Berni P., Aquat. Living Resour., 14, 367-374 (2001).

33) Cho S. Y., Sim J. S., Jeong C. S., Chang S. Y., Choi D. W., Toida T., Kim Y. S., Biol. Pharm. Bull., 27, 47-51 (2004).

34) Syrokou A., Tzanakakist G., Tsegenidis T., Hjerpe A., Karamanos N. K., Cell Prolif., 32, 85-99 (1999).

35) Kyriakis J. M., Avruch J., J. Biol. Chem., 271, 24313 -24316 (1996).

36) Lovicu F. J., McAvoy J. W., Development, 128, 5075-5084 (2001).

37) Asada M., Shinomiya M., Suzuki M., Honda E., Sugimoto R., Ikekita M., Imamura T., Biochim. Biophys. Acta, 1790, 40-48 (2009).

38) Cai S., Liu Y., Zheng S. X., Prestwich G. D., Biomaterials, 26, 6054 6067 (2005).

39) Dale P. D., Sherratt J. A., Maini P. K., Bull. Math. Biol., 59, 10771100 (1997).

40) Kuhn M. A., Smith P. D., Hill D. P., Ko F., Meltzer D. D., Vande Berg J. S., Robson M. C., Wound Repair Regen., 8, 270-276 (2000).

41) Beurden H. E., Snoek P. A., Von den Hoff J. W., Torensma R., Kuijpers-Jagtman A. M., Wound Repair Regen., 11, 55-63 (2003). 